\title{
Indoor air decontamination system and reduction of microorganism emissions into the atmosphere
}

\author{
V.S. Shkrabak ${ }^{1}$, A.A. Popov ${ }^{1}$, V.G. Enikeev ${ }^{1}$, E.I. Gavrikova ${ }^{2}$, and R.V. Shkrabak ${ }^{1}$ \\ ${ }^{1}$ St-Petersburg State Agrarian University, St. Petersburg - Pushkin 196601, Russia \\ ${ }^{2}$ Orel State Agrarian University named after N.V. Parakhin, Orel 302019, Russia
}

\begin{abstract}
The paper considers the effect of sanitary and hygienic condition of occupational environment, namely the factor of increased microbial contamination, on temporary disability and reduction of labor efficiency. In this regard, it is necessary to improve the methodology and technical support of disinfection methods in order to reduce labor intensity and increase the efficiency of equipment and disinfectants. The developed deflector model serves to reduce the emissions of microorganisms into the atmosphere and improves the environmental situation. The proposed design of the ultrasonic system makes it possible to improve user experience due to the possibility to control the flow rate of the working fluid and preparations. According to the results of the experiment, the disinfection agent based on hydrogen peroxide, silver salt and a furocoumarin solution in ethyl alcohol with the use of the developed ultrasonic atomizer reduced the total microbial contamination by 8 times on average.
\end{abstract}

\section{Introduction}

Being one of the determining factors for the health of workers the production environment has a significant influence on occurrence and course of respiratory diseases. WHO experts forecast that in a few years about $18 \%$ of all fatal diseases will be respiratory (pneumonia, cancer and chronic obstructive pulmonary disease) [1]. According to available statistics, the fatal outcome of chronic occupational diseases with a probability of up to $70 \%$ (depending on the year of observation) is a consequence of severe respiratory pathology. The registration of respiratory diseases leading to disability of the working population shows that in the territory of Russia the respiratory diseases form the primary occupational incidence by $25-30 \%$ [2].

Agriculture, manufacturing and mining are the leading sectors of economic activity with increased number of workers having registered occupational respiratory diseases. Dust of complex composition, with mineral and organic components, present in the air of livestock premises, is the main cause of occupational respiratory diseases [3]. Besides, gaseous products of excreta and animal life decomposition, residues of chemical compounds used in disinfection of premises, lead to irritating effects on mucous membranes and further to subatrophic and atrophic processes of upper respiratory airway damage [4].

According to other studies, in livestock industry due to direct contact with a large number of animals that need servicing, veterinary treatment, disinfection of premises, the peculiarities of respiratory system pathology are related to a biological harmful factor, in particular, to increased microbial contamination of the working air [5]. Dust aerosols with a dispersed part consisting of bacteria, viruses, fungus spores located in a breathing zone of workers pose a special danger to health. Temporary disability caused by respiratory diseases in livestock workers amounts to $26.3-52.4 \%$ of the total morbidity, and accordingly, from 15.7 to $35.6 \%$ of day of disability [6].

\section{Results and discussion}

The development of computer and information technologies makes it possible to use them at the present stage to estimate labor losses associated with biological production risks.

Our proposed assessment of diseases with temporary disability depending on the concentration of microbial aerosol in the air of the working zone is a software for quantifying and predicting the duration of diseases of farm workers and livestock and poultry production complexes.

The study revealed that high concentration of microbial aerosol of livestock enterprises, even in the absence of pathogenic forms of microorganisms, significantly reduces the level of immunity of workers and causes their predisposition to home infections.

In order to determine the duration of diseases with temporary disability depending on the concentration of microbial aerosol in the air of production premises, the study is based on personal research data, literary sources, as well as materials on the duration of diseases with temporary disability contained in statistical reports.

\footnotetext{
* Corresponding author: v.shkrabak@mail.ru
} 
The analysis was carried out at agricultural enterprises with various technological processes, equipment, production volumes, which besides microbiological allowed offsetting the influence of other harmful production factors on morbidity.

Function: $\mathrm{y}=0.004 \mathrm{x}^{2}-0.204 \mathrm{x}+10.67$ with high reliability $\left(\mathrm{R}^{2}=0.99\right)$ of approximations describes the empirical dependence of duration of diseases with temporary disability on microbial content of air (th. $\left.\mathrm{c} / \mathrm{m}^{3}\right)$.

The program converts the following opportunities:

- entry of the number of microbial cells in $1 \mathrm{~m}^{3}$ of air;

- automatic calculation of the duration of diseases with temporary disability;

- easy and fast data reset.

The developed program does not require installation.

In addition to the direct impact on the health of workers, livestock complexes can release concentrated microbial aerosol during the day in the absence of properly organized ventilation (Figure 1) thus causing various infections.

Figure 2 shows the empirical dependence of microorganism emissions by agricultural enterprises on microbial contamination of air in working premises.

Considering the fact that natural ventilation is quite widely used in agricultural production due to the fact that it is characterized by relatively low capital and operational costs, absence of noise and vibration, the current task is to develop deflectors - devices that create additional induced draught.

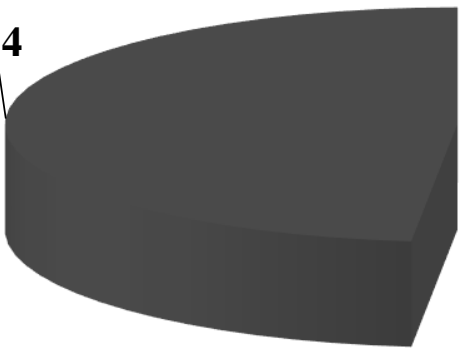

The structure shown in Fig. 3 (vertical section) is a deflector designed for livestock premises with high microbial contamination $\left(60-100 \mathrm{c} / \mathrm{m}^{3}\right)$ and equipped with natural ventilation [7].

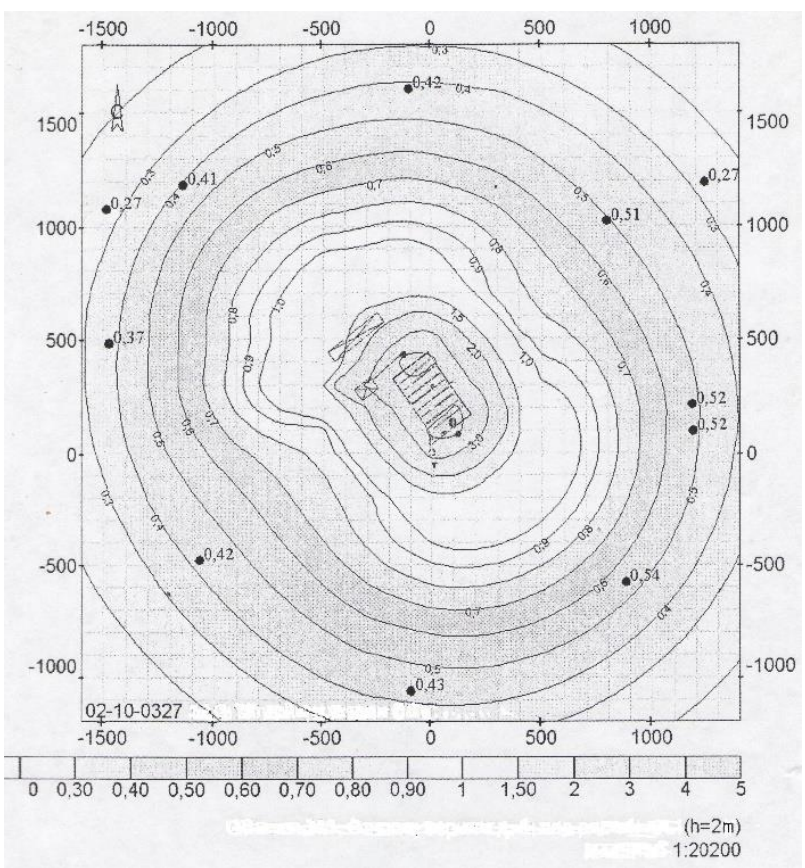

Fig. 1. Microbial aerosol emission diagram Feeding shop of a pig-breeding plant of ZAO Orelselprom, Mtsenskiy district of Orel Region

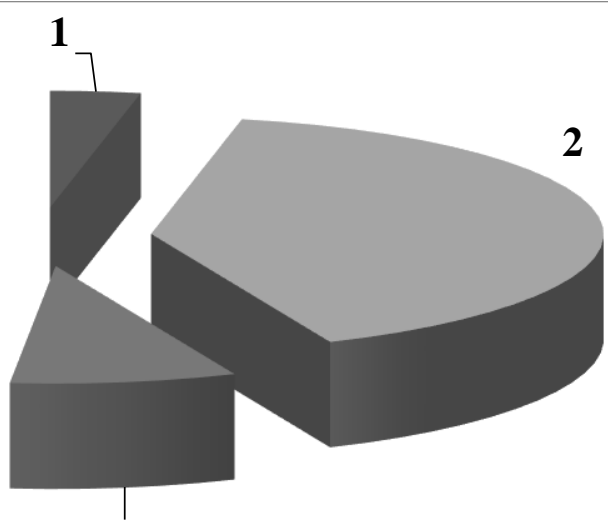

3

1 - meat processing plants meat processing plants (3\%), 2 - veterinary and sanitary recycling plants (40\%), 3 - dairy farms $(8 \%), 4$ - pig-breeding complexes $(49 \%)$

Fig. 2. Empirical dependence of microorganism emissions by agricultural enterprises on microbial contamination of air in working premises

The deflector consists of a diffuser 1 - pipe section, scanning of which represents a truncated cone installed on a ventilation pipe; a ring 3 - external cylinder and a ventilation hood 5 , which serves to protect the exhaust channel from moisture ingress.

Efficient operation of drawing is ensured by the depression zone created by wind flows in a ring 3 from a downwind side.

Optimal aerodynamic characteristics are provided by specially calculated dimensions and gaps of structural elements of a device. The thermal insulation layer 6 and a shield 2 create an obstacle for cooling a ventilation hood 5 thus preventing condensation and wetting of a cartridge filter 8 since its filtering capacity can be completely lost.

If necessary, the cartridge filter 8 is replaced as follows. The ventilation hood 5 is lifted, clamping elements 10 are removed, a seal and a cartridge filter 8 are recovered. 


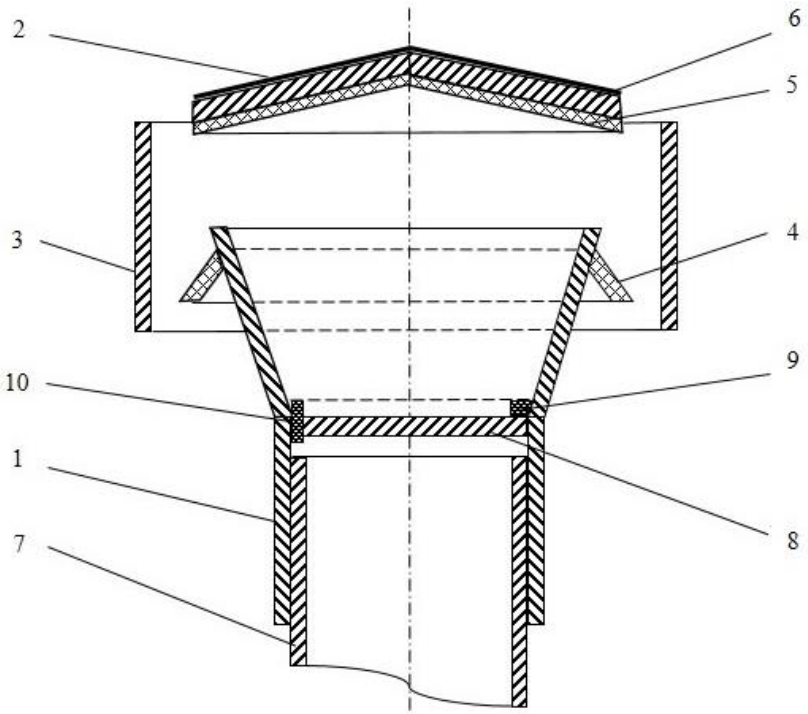

Fig. 3. Deflector for livestock premises with increased microbial air contamination in working rooms: 1 - diffuser; 2 - shield; 3 - ring; 4 - cone shield; 5 - ventilation hood; 6 - thermal insulation layer; 7 - ventilation pipe; 8 - cartridge filter; 9 - seal; 10 - clamping element

The use of a cartridge filter 8 significantly reduces the release of dust and microorganisms into the environment.

However, despite the fact that ventilation can be called the most common method of mechanical removal of microorganisms, there is data [8] confirming that the use of general ventilation systems leads to dilution of air in working zones, but does not clean it completely. It shall also be considered that some contaminated air is returned to the room through external recirculation and thus reduces the overall ventilation efficiency.

Other disinfection methods (short-wave ultraviolet radiation, ozonation, use of solutions of lime chloride, soda ash, formalin) are sources of contamination of production space and environment with chemical toxic compounds having negative effect on the body of workers.

Mechanical cleaning makes it possible to remove pollution from the surface of objects and creates a good contact of used disinfectants with an object surface. Some disinfectants, such as lactic acid, are used by evaporation. Others, for example hydrogen peroxide, by fine spraying [9].

The disadvantage of polydisperse aerosols obtained via thermal and thermomechanical devices is the fact that due to thermal decomposition the preparations partially lose their efficiency. Mechanical atomizers based on the crushing method do not have this disadvantage. Ultrasonic devices meet the requirements of monodispersity to the fullest extent possible. Besides, they allow rapid control of an average diameter of the generated aerosols. The ultrasound power determines the rate of an aerosol mist, while the frequency - dispersion.

One of the common substances used in disinfection is hydrogen peroxide, the advantage of which, apart from a wide antimicrobial spectrum of action, is environmental safety caused by the fact that the peroxy group has low stability and easily breaks into oxygen and water [10].
However, the efficiency of aerosol treatment methods directly depends not only on the composition of used means, but also on technical characteristics of aerosol production structures.

Due to the fact that the possibility of controlling the flow rate of the working fluid and preparations will increase the convenience of operation, we have developed the following design of the ultrasonic atomizer of disinfecting agents (Fig. 4).

The proposed ultrasonic atomizer [11] includes an atomizing chamber 1 equipped with an ultrasonic piezoelectric radiator 2 ; a phase shifting circuit 5 including a resistor 6; parallel oscillating circuit formed by capacitor 8 and primary winding of a transformer 7 connected through a capacitor 10 cutting off DC voltage to an emitter of a transistor 3. At the same time, a quartz resonator 9 connects the secondary winding of a transformer 7 and a base of a transistor 3. Besides, the ultrasonic atomizer includes the following circuits: matching circuit formed by a capacitor 11 , an autotransformer 13, a variable induction coil 12 and a circuit 14 applying a bias to a base of a transistor 3, including a series-connected constant and variable resistor, and a capacitor 15 .

The detector is made on two generators A and B consisting of DD1 integrated-circuit elements, resistors $17,19,20$, capacitors 18,21 ; an emitter repeater 22 , a device 24 to convert electric oscillations to acoustic vibrations, a trimming resistor 23, and a sensor represented by two sensory elements (plates) 16 placed in a reservoir with a controlled solution.

Power supply of ultrasonic atomizer supplies displacement to the base of a transistor 3, transformer coils 7 are switched on, which ensures self-excitation and rotation of a phase of $180^{\circ}$. The phase-shifting circuit 5 receives feedback voltage from an emitter of a transistor 3 through the DC cutoff capacitor 10 . The voltage phase depends on settings of the oscillating circuit (primary winding of a transformer 7 and a capacitor 8 and a resistor 6 connected to it in series), which form a phase changer. The operating frequency of the ultrasonic atomizer varies depending on the phase of the feedback voltage, which in turn varies with the inductance of the oscillating circuit from the rotation of the core of a transformer 7. Via a quartz resonator 9 the feedback voltage is supplied to the base of a transistor 3 from the secondary winding of a transformer 7 .

The generator $\mathrm{A}$ is not working until its input control voltage corresponds to the logic level 0 since the resistance of sensory elements 16 (plates) placed in a tank with controlled solution is low.

The voltage corresponding to the level of logic 1 obtained at the output of a divider assembled on sensory elements 16 and a resistor 17 results from sharp increase of resistance of the sensory elements 16 when the solution in the tank falls below their level. In this case, pulses generated by the generator A at a frequency of about $5 \mathrm{~Hz}$ will trigger the generator $\mathrm{B}$. The pulses generated by the generator B at a frequency of $1000 \mathrm{~Hz}$ are supplied to the device 24 to convert electric oscillations into sound vibrations. The trimming resistor 23 adjusts the sound volume. 


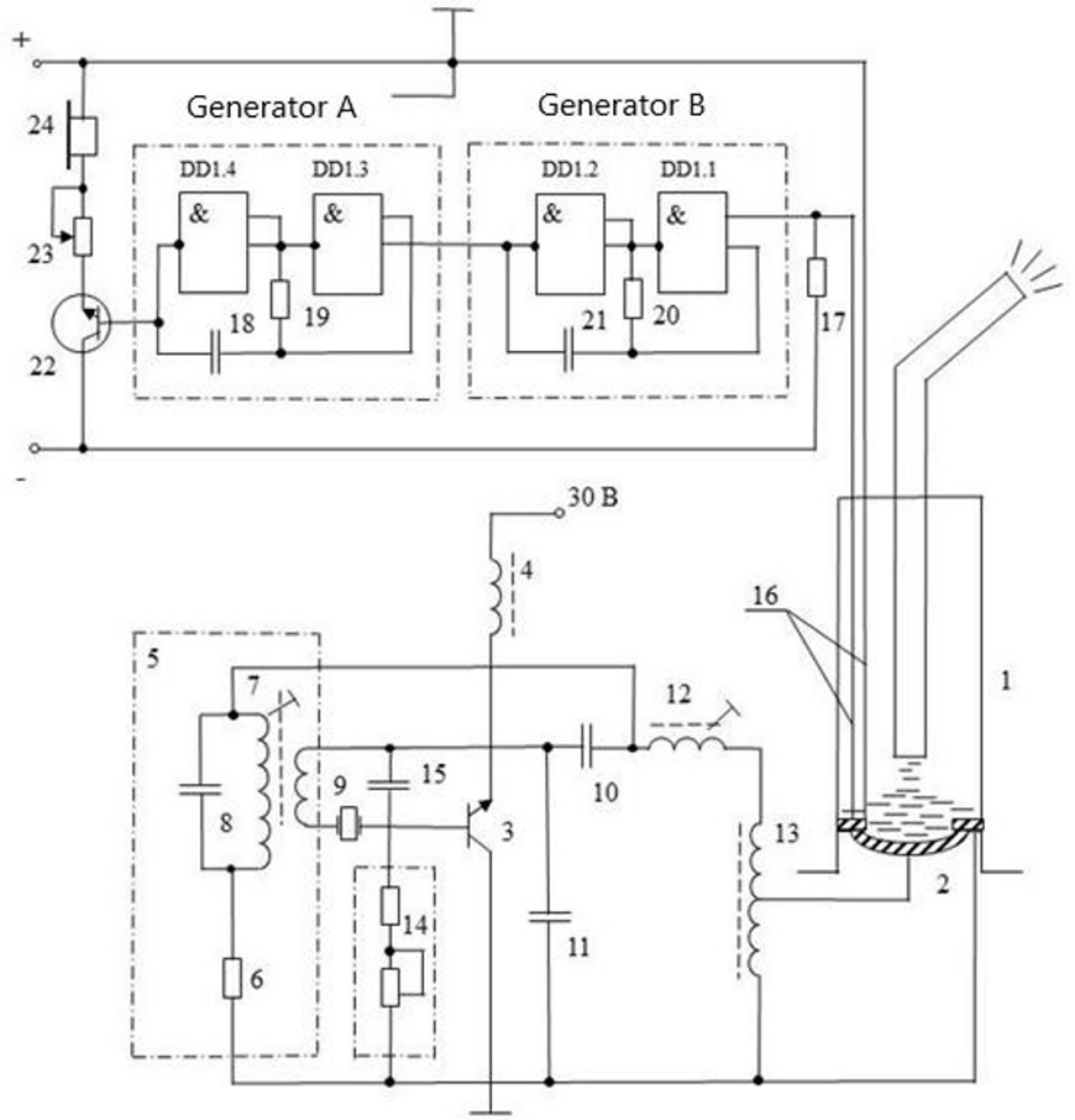

Fig. 4. Ultrasonic atomizer with signalling device: 1 - atomizing chamber; 2 - ultrasonic piezoelectric radiator; 3 , 14 - transistor; 4 -induction coil; 5 - phase shifting circuit; $6,17,19,20$ - resistors; 7 - transformer; 8, 11, 15, 18, 21 - capacitors; 9 - quartz resonator; 10 - DC cutoff capacitor; 12 - variable induction coil; 13 - autotransformer; 16 - sensory elements (plates); 22 - emitter repeater; 23 - trimming resistor; 24 - device to convert electric oscillations to acoustic vibrations

The efficiency of ultrasonic atomizer for disinfection in livestock premises was tested on Escherichia coli (E. coli) bacteria according to the following procedure. E. coli cells were prepared from a one-day culture via limiting dilution culture. A suspension containing E. coli in the amount of 1 bln CFU per $100 \mathrm{ml}$ was sprayed into the air to a concentration of 50,000. CFU/m ${ }^{2}$ and sequentially treated with hydrogen peroxide aerosol $\left(\mathrm{H}_{2} \mathrm{O}_{2}\right.$ concentration $\left.-0.1 \mathrm{~g} / \mathrm{l}\right)$ obtained with the present ultrasonic atomizer. The decontamination effect (E. coli death) was $57.0 \%$.

In order to increase the efficiency of air decontamination in rooms, we obtained a composition with improved antimicrobial activity with the following ratio of components, wt $\%$ : hydrogen peroxide -5 ; silver salt $-1 ; 5 \%$ solution of furocoumarin in ethyl alcohol 10 ; water - the rest.

A wide range of antimicrobial action of silver, low toxicity, lack of resistance to it in most pathogenic microorganisms and non-allergy of silver allow using it as an effective and harmless disinfectant [12].

Derivatives of plant furocoumarin have antibacterial activity and prevent biofilm formation [13, 14].
A disinfection agent was prepared by mixing the listed ingredients in specified ratios (wt \%). The Ammifurin agent was used as a source of furocoumarin. Silver nitrate was used from silver salts.

In enclosed space, disinfectant was sprayed in the air. The total microbial contamination was determined by aspiration using the Krotov's device. Air was sampled to determine its bacterial contamination before and after photocatalytic air decontamination. In order to determine the content of yeast-like and mold-like fungi, seeding was carried out on Saburo medium, total microbial contamination on plain agar. The air flow rate made $25 \mathrm{l} / \mathrm{min}$ over $40 \mathrm{~min}$. The seeded media were kept in a thermostat at $(37 \pm 1){ }^{\circ} \mathrm{C}$ for $24 \mathrm{~h}$, then at room temperature for $24 \mathrm{~h}$, and then the grown bacteria colonies were counted and the colony forming units (hereinafter referred to as CFU) contained in $1 \mathrm{~m}^{3}$ of air were calculated.

Air handling with the proposed agent reduces the total microbial contamination and contamination with mold fungi (Tables 1, 2). 
Table 1. Bacterial air contamination when using the proposed agent for air disinfection in enclosed space (total microbial count, $\mathrm{CFU} / \mathrm{m}^{3}$ ).

\begin{tabular}{|c|c|c|c|c|}
\hline & \multicolumn{4}{|c|}{ Sampling interval } \\
\hline & $\begin{array}{c}\text { before } \\
\text { treatment }\end{array}$ & $\begin{array}{c}\text { in 1 } \\
\text { day }\end{array}$ & $\begin{array}{c}\text { in 8 } \\
\text { days }\end{array}$ & $\begin{array}{c}\text { in 15 } \\
\text { days }\end{array}$ \\
\hline Control & 410 & 415 & 415 & 424 \\
\hline Experiment & 410 & 310 & 184 & 103 \\
\hline
\end{tabular}

Table 2. Fungi contamination during treatment with the proposed agent for disinfection of air environment in enclosed space (total fungi count, diaspore $/ \mathrm{m}^{3}$ ).

\begin{tabular}{|c|c|c|c|c|}
\hline & \multicolumn{4}{|c|}{ Sampling interval } \\
\hline & $\begin{array}{c}\text { before } \\
\text { treatment }\end{array}$ & $\begin{array}{c}\text { in } 1 \\
\text { day }\end{array}$ & $\begin{array}{c}\text { in } 8 \\
\text { days }\end{array}$ & $\begin{array}{c}\text { in } 15 \\
\text { days }\end{array}$ \\
\hline Control & 65 & 71 & 69 & 71 \\
\hline Experiment & 65 & 51 & 29 & 8 \\
\hline
\end{tabular}

The total microbial contamination is reduced by an average of 4 times, the content of mold fungi - by 8 times.

The tables show that once the proposed agent is applied for air disinfection the level of indoor contamination is significantly reduced.

\section{Conclusion}

The study makes it possible to recommend disinfection in production premises with the proposed composition with improved antimicrobial activity based on hydrogen peroxide, silver salt and furocoumarin solution in ethyl alcohol using the developed ultrasonic sprayer. The use of proposed eco-friendly disinfectant will reduce the economic costs of measures related to the elimination of infectious diseases of humans and animals. The developed deflectors will improve their operational reliability, environmental friendliness, simplify the design, improve the working conditions within the agroindustrial complex. The use of the developed deflector makes it possible to significantly reduce the emission of dust and microorganisms into the environment, which generally improves the environmental situation.

\section{References}

1. D.M. Mannino, A.S. Buist, Global burden of COPD: risk factors, prevalence, and future Trends, Lancet, 370, 65-73 (2007)

2. N.F. Metarov, ed. Professional pathology (GEOTAR-Media, Moscow, 2011)
3. V.F. Spirin, B.T. Velichkovsky, O.S. Vasilyeva, Occupational Health and Respiratory Diseases in Livestock and Fodder Workers (Saratov, 2002)

4. N.Z. Yusupova, N.N. Shamsiyarov, F.F. Dautov, Hygienic Assessment of Risk Factors for Health of Workers of Livestock Complexes, Labor. Med. and Industr. Ecology, 2, 9-11 (2012)

5. V.S. Shkrabak, E.I. Gavrikova, Measures to reduce the contact of workers with microorganisms, In the collection: Improvement of ways to prevent industrial risks, dynamic reduction and elimination of injuries and morbidity of agribusiness workers, Collection of sci. works of the int. sci. and pract. conf. 9-12 (Ministry of Agriculture, St. Petersburg State Agrarian University, 2017)

6. V.P. Kolosov, V.B. Kozhaeva, Epidemiology and Clinical Features of the Course of Diseases of the Broncho-Pulmonary System in Livestock Workers, Bull. of Phys. and Pathology of Breathing, 8, 27-40 (2001)

7. E.I. Gavrikova, K.S. Laktionov, Deflector, Patent RU 2485412 (2012)

8. V.I. Bezzubov, D.N. Khodosovsky, A.S. Petrushko, Improvement of ventilation systems and creation of microclimate in the farrowing shop of pig breeding complexes, Zootech. Sci. of Belarus, 53(2), 127-134 (2018)

9. A.P. Kondratov, M.V. Ryabkin, A.V. Platonov, Antimicrobial efficiency of physical and chemical air disinfection methods, Disinfection, 2, 40-43 (2006)

10. E.S. Matreninskaya, New generation of hydrogen peroxide disinfectants, Med.1 alphabet, Epidemiol. and Sanitat., 1, 40 (2011)

11. E.I. Gavrikova, Ultrasonic Atomizer, Patent RU 141355 (2014)

12. O.V. Mosin, Bactericidal properties of colloidal silver nanoparticles, Nanotechnol. Ecol. Product., 6(25), 54-59 (2013)

13. I.V. Shirokikh, L.G. Burova, A.V. Lipeeva, E.E. Schultz, Study of antibacterial properties of peutsedanin derivatives concerning Staphylococcus aureus in vitro, Siber. med. messenger, 2, 8-12 (2018)

14. B. Girennavar, M.L. Cepeda, K.A. Soni et al., Grapefruit juice and its furocoumarins inhibits autoinducer signaling and biofilm formation in bacteria, Int. J. Food Microbiol., 125, 204-208 (2008) 